\title{
Características de Carcaça e da Carne de Novilhos Superprecoces de Três Grupos Genéticos, Gerados por Fêmeas de Dois Anos
}

\section{Fabiano Nunes Vaz ${ }^{1}$, João Restle ${ }^{2}$, Paulo Santana Pacheco ${ }^{3}$, Aline Kellermann de Freitas ${ }^{4}$, Luis Antero de Oliveira Peixoto ${ }^{4}$, Charles de Oliveira Carrilho ${ }^{4}$}

RESUMO - O objetivo deste trabalho foi estudar as características quantitativas e qualitativas da carcaça e da carne de novilhos Hereford (H), 1/2 Jersey 1/2 H (JH) e 5/8 H 3/8 Nelore (HN). Foram utilizados 24 machos castrados, sendo oito de cada grupo genético, alimentados em confinamento desde o desmame, aos sete meses, até o abate aos quatorze meses de idade. O peso de abate foi similar entre os genótipos, mas os pesos de carcaça quente e carcaça fria foram maiores nos H (220,6 kg e 195,1 kg) e HN (200,8 kg e 196,2 $\mathrm{kg}$ ) que nos novilhos JH (171,8 kg e 167,8 kg). Também os rendimentos de carcaça quente e carcaça fria, a conformação e área do músculo Longissimus dorsi foram superiores nos animais $\mathrm{H}$ (respectivamente, 52,79\%, 51,35\%, 9,88 pontos e $55,46 \mathrm{~cm}^{2}$ ) e $\mathrm{HN}_{(\mathrm{respecti}-}$ vamente, $54,08 \%, 52,80 \%, 10,20$ pontos e $56,97 \mathrm{~cm}^{2}$ ) em relação aos novilhos JH (respectivamente, 49,56\%, 48,38\%, 7,75 pontos e $\left.46,89 \mathrm{~cm}^{2}\right)$. O comprimento de perna foi menor nos novilhos JH $(61,4 \mathrm{~cm})$ em relação aos $\mathrm{HN}(63,9 \mathrm{~cm})$. Os grupos genéticos foram similares nas porcentagens de músculo, osso e gordura, assim como na espessura de gordura subcutânea, maturidade fisiológica, cor, textura e marmoreio da carne. Animais HN apresentaram maior perda ao descongelamento $(9,62 \%)$ em relação aos $\mathrm{H}(7,48 \%)$ e JH $(7,17 \%)$. Não houve diferença significativa para características sensoriais, força de cizalhamento e teor de colágeno total do músculo Longissimus dorsi entre os genótipos.

Palavras-chave: Braford, características sensoriais, composição da carcaça, Hereford, Jersey

\section{Carcass and Meat Characteristics of Young Steers of Three Genetic Groups, Produced by Two Years Old Females}

\begin{abstract}
The objective of this work was to study carcass and meat quantitative and qualitative characteristics of Hereford $(\mathrm{H}), 1 / 2$ Jersey $1 / 2 \mathrm{H}(\mathrm{JH})$ and 5/8 H 3/8 Nellore (HN) steers. Twenty-four castrated males, being eight of each genetic group, fed in feedlot since the weaning at seven months until the slaughter at fourteen months of age, were used. Slaughter weight was similar among genotypes, but the hot and the cold carcass weights were higher for the $\mathrm{H}(220.6 \mathrm{~kg}$ and $195.1 \mathrm{~kg})$ and $\mathrm{HN}$ steers (200.8 kg and $196.2 \mathrm{~kg}$ ) than for the JH steers $(171.8 \mathrm{~kg}$ and $167.8 \mathrm{~kg}$ ). Also hot and cold dressing percentage, conformation and Longissimus dorsi area were superior for the $\mathrm{H}$ (respectively, 52.79\%, 51.35\%, 9.88 points and $55.46 \mathrm{~cm}^{2}$ ) and $\mathrm{HN}$ steers (respectively, $54.08 \%$, $52.80 \%, 10.20$ points and $56.97 \mathrm{~cm}^{2}$ ) in relation to the $\mathrm{JH}$ steers (respectively, $49.56 \%, 48.38 \%, 7.75$ points and $46.89 \mathrm{~cm}^{2}$ ). Leg length was smaller for the $\mathrm{JH}(61.4 \mathrm{~cm})$ than for the $\mathrm{HN}$ steers $(63.9 \mathrm{~cm})$. Genetic groups were similar in muscle, bone and fat percentages, subcutaneous fat thickness, physiological maturity, meat color, texture and marbling. HN animals showed higher thawing loss $(9.62 \%)$ than the $\mathrm{H}(7.48 \%)$ and $\mathrm{JH}$ animals $(7.17 \%)$.No significant differences among genetic groups were observed for sensorial characteristics, Shear force and total collagen in the Longissimus dorsi muscle.
\end{abstract}

Key Words: Braford, carcass composition, Hereford, Jersey, sensorial characteristics

\section{Introdução}

Ao se buscarem melhores índices de produtividade na pecuária de corte, surge a necessidade da redução da idade de abate dos machos e de entoure das novilhas. Nesse contexto, a precocidade da raça Hereford possibilita que esta e suas cruzas sejam genótipos bastante utilizados em sistemas de produção que visam o abate dos machos entre 18 e 22 meses de idade e o entoure das novilhas por volta dos quatorze meses de idade. Entretanto, estes sistemas precisam estar amparados em bons níveis nutricionais e genéticos.

Também em busca do aumento de produtividade da pecuária de corte, já há algumas décadas busca-se explorar a heterose do cruzamento e aliar os índices produtivos de raças taurinas com a rusticidade das raças zebuínas. No sul dos Estados Unidos, foram

\footnotetext{
1 Zootecnista, MS, Doutorando CEPAN - UFRGS. Consultor licenciado da Progepec Consultores Associados Ltda. UFSM, Campus de Camobi, CEP 97119-105, Santa Maria-RS. E.mail: fnvaz@terra.com.br

2Engenheiro-Agrônomo, PhD, Bolsista do CNPq. E.mail: jorestle@ccr.ufsm.br

3 Zootecnista, Aluno do curso de Pós-Graduação em Zootecnia - UFSM. Bolsista PIBIC-CNPq.

${ }^{4}$ Aluno do curso de Graduação em Zootecnia - UFSM. Bolsista IC.
} 
testados diferentes genótipos cruzando Hereford com zebuínos, chegando-se ao melhor desempenho em animais 5/8 Hereford 3/8 zebu, fixando-se, naquele país, a raça sintética Braford (Adams, 1973).

Com a redução da idade de entoure das novilhas, cresce a preocupação por parte do pecuarista em produzir um bezerro que, ao nascer, apresente tamanho condizente à área pélvica dessas fêmeas, que ainda se encontram em desenvolvimento. A fecundação de novilhas com sêmen de raças de pequeno porte surge como uma saída para a redução da ocorrência de partos distócicos. A Jersey é a menor entre as raças bovinas aperfeiçoadas e os bezerros apresentam baixo peso ao nascer (Santiago, 1984). O resultado do cruzamento de novilhas Hereford com touros Jersey são bezerros sem finalidade reprodutiva dentro do rebanho, portanto, a sua terminação deve ocorrer o mais cedo possível, sendo necessário utilizar altos níveis alimentares, encontrados na suplementação em pastagens cultivadas ou em confinamento (Pascoal et al., 1999).

Referindo-se ao confinamento para a terminação de bezerros aos quatorze meses, Restle et al. (1999b) cita que esse manejo permite que estes alcancem peso de carcaça e acabamento dentro dos limites exigidos pelos frigoríficos. Os mesmos autores complementam afirmando que, ao reduzir a idade ao abate, o consumidor é beneficiado com uma carne de melhor qualidade e o produtor possui melhor aproveitamento de área, pois elimina uma categoria dentro da propriedade, podendo ocupar esse espaço com ventres de cria.

São poucas as informações disponíveis sobre as características da carcaça dos animais frutos destes cruzamentos e comparados com animais definidos, e também escassos são os trabalhos que comparam animais oriundos de sistema de exploração intensiva, em que os bezerros gerados por fêmeas acasaladas aos dois anos destinam-se ao abate aos quatorze meses. Os objetivos deste trabalho foram avaliar as características qualitativas da carcaça e da carne de novilhos terminados em confinamento e abatidos aos quatorze meses, provenientes de dois tipos de cruzamentos, e compará-los ao Hereford puro.

\section{Material e Métodos}

O experimento foi conduzido no Setor de Bovinocultura de Corte do Departamento de Zootecnia da Universidade Federal de Santa Maria, localizada no município de Santa Maria, Rio Grande do Sul.

Foram avaliados três grupos genéticos de novilhos: Hereford (H), 1/2 Jersey 1/2 Hereford (JH) e 5/8 Hereford 3/8 Nelore (HN). Utilizaram-se 24 animais castrados, tomados ao acaso do rebanho da Estância Guatambu, localizada no município de Dom Pedrito, RS. Os animais foram mantidos ao pé da vaca, em campo nativo melhorado, até os sete meses de idade, quando foram desmamados e levados ao confinamento, com peso médio inicial de $163,3 \mathrm{~kg}$, onde permaneceram durante 194 dias, sendo então abatidos aos quatorze meses de idade.

Durante todo o período de confinamento, foi fornecida uma dieta contendo $12 \%$ de proteína bruta. A proporção média de volumoso:concentrado foi de 54:46, com base na matéria seca, utilizando-se como volumoso silagem de sorgo forrageiro e, como concentrado, milho em grão moído, farelo de soja, farelo de arroz desengordurado (FAD), farinha de carne e minerais, conforme mostra a Tabela 1.

Antes do embarque para o frigorífico, os animais foram pesados após jejum de 12 horas. Por ocasião do abate, as carcaças foram identificadas, pesadas, lavadas e levadas ao resfriamento a $0^{\circ} \mathrm{C}$ por 24 horas. Decorrido esse tempo, as carcaças foram retiradas da câmara fria e novamente pesadas, sendo logo após realizada a medição do $\mathrm{pH}$ e as avaliações da maturidade fisiológica, conformação e medidas de desenvolvimento da carcaça (Müller, 1987).

O músculo Longissimus dorsi foi seccionado na altura da $12^{\mathrm{a}}$ costela e, após exposição ao ar por 20 minutos, foram avaliadas subjetivamente as características cor, textura e marmoreio, além de ser medida a espessura de gordura subcutânea, segundo as técnicas descritas por Müller (1987). Para determinação da composição da carcaça em osso, músculo e gordura, foi extraída uma peça correspondendo às 9-10-11 a costelas, segundo a metodologia proposta por Hankins \& Howe (1946).

A porção de músculo Longissimus dorsi extraída dessa amostra foi congelada, sendo que, após um período de aproximadamente 30 dias de congelamento, foram retirados dois bifes de $2,5 \mathrm{~cm}$ de espessura e um de $0,5 \mathrm{~cm}$ de espessura de cada amostra do músculo ainda congelado. Uma das fatias de $2,5 \mathrm{~cm}$ foi utilizada para determinação da perda ao descongelamento e da perda à cocção. Também desta fatia foram retiradas três amostras de feixes de fibras musculares, com área de $1 \mathrm{~cm}^{2}$, cortadas perpendicularmente às fibras, sendo que, em cada uma, foram

R. Bras. Zootec., v.31, n.5, p.1973-1982, 2002 
Tabela 1 - Composição da dieta nos diferentes períodos (porcentagem da matéria seca)

Table 1 - Diet composition in the different periods (dry matter percentage)

\begin{tabular}{|c|c|c|c|c|c|c|c|}
\hline \multirow[t]{2}{*}{$\begin{array}{l}\text { Ingrediente } \\
\text { Ingredient }\end{array}$} & \multicolumn{7}{|c|}{$\begin{array}{l}\text { Período } \\
\text { Period }\end{array}$} \\
\hline & 1 & 2 & 3 & 4 & 5 & 6 & 7 \\
\hline $\begin{array}{l}\text { Silagem de sorgo } \\
\text { Sorghum silage }\end{array}$ & 70,00 & 65,00 & 60,00 & 55,00 & 50,00 & 45,00 & 40,00 \\
\hline $\begin{array}{l}\text { Farelo de soja } \\
\text { Soybean meal }\end{array}$ & 10,31 & - & - & - & 4,40 & 4,26 & 4,23 \\
\hline $\begin{array}{l}\text { Farinha de carne } \\
\text { Meat meal }\end{array}$ & - & 9,14 & 8,98 & 8,77 & 4,40 & 4,26 & 4,23 \\
\hline $\begin{array}{l}\text { FAD } \\
\text { Defatted rice meal }\end{array}$ & 11,33 & 10,75 & 10,23 & 10,03 & 11,01 & 11,15 & 10,18 \\
\hline $\begin{array}{l}\text { Grão de milho } \\
\text { Corn grain }\end{array}$ & 7,42 & 14,17 & 19,89 & 25,31 & 29,29 & 34,43 & 40,49 \\
\hline $\begin{array}{l}\text { Calcário calcítico } \\
\text { Limestone }\end{array}$ & 0,59 & 0,58 & 0,57 & 0,56 & 0,58 & 0,59 & 0,56 \\
\hline $\begin{array}{l}\text { Sal comum } \\
\text { Salt }\end{array}$ & 0,35 & 0,36 & 0,33 & 0,33 & 0,32 & 0,31 & 0,31 \\
\hline $\begin{array}{l}\text { Total } \\
\text { Total }\end{array}$ & 100,00 & 100,00 & 100,00 & 100,00 & 100,00 & 100,00 & 100,00 \\
\hline
\end{tabular}

realizadas duas leituras pelo aparelho "Warner-Bratzler Shear" para determinação da força de cisalhamento.

O outro bife, assado juntamente com o primeiro, foi cortado ainda quente, em cubos de $2 \mathrm{~cm}^{3}$, os quais foram distribuídos para um painel de cinco degustadores treinados, que avaliaram subjetivamente as características maciez, palatabilidade e suculência. O terceiro bife, com espessura de $0,5 \mathrm{~cm}$, foi reservado para determinação do teor de colágeno total do músculo Longissimus dorsi, em laboratório.

O delineamento utilizado foi o inteiramente casualizado, com oito repetições por grupo genético. O modelo estatístico utilizado foi:

$$
Y_{i j}=\mu+G_{i}+e_{i j}
$$

em que: $Y_{i j}=$ observação do n-ésimo animal, pertencente ao i-ésimo grupo genético; $\mu=$ média geral de todas as observações; $\mathrm{G}_{\mathrm{i}}=$ efeito do i-ésimo grupo genético; $\mathrm{e}_{\mathrm{ij}}=$ erro aleatório associado a cada observação.

Por meio do pacote estatístico SAS (1990), os dados foram submetidos à análise de variância e as médias que mostraram diferença significativa (5\%) foram submetidas ao teste Tukey a 5\% de significância.

\section{Resultados e Discussão}

Na Tabela 2, são apresentados os valores médios para as características relacionadas ao peso de abate, pesos de carcaça, quebra ao resfriamento, rendimentos de carcaça e porcentagem dos cortes comerciais.
Observa-se que o peso de abate não diferiu significativamente entre os grupos genéticos, embora os animais JH tenham sido $33 \mathrm{~kg}$ mais leves $(\mathrm{P}>0,0823)$ que os animais $\mathrm{H}$.

Os menores rendimentos de carcaça quente e fria ( $\mathrm{P}<0,0001)$ do genótipo JH, aliado ao seu menor peso de abate, resultaram em pesos de carcaça quente e fria inferiores aos dos novilhos $\mathrm{He} \mathrm{HN}$. Contrastando animais $\mathrm{H}$ definidos e $\mathrm{H}$ cruzados com uma raça leiteira (Holandês), Becker (1978) verificou maior rendimento de carcaça nos animais puros, mesmo que estes tenham apresentado menor peso de abate. Este autor relata que o maior volume do trato digestivo dos mestiços Holandês prejudicou seu rendimento de carcaça. Ao verificarem menor rendimento de carcaça fria em animais Holandês $(54,82 \%)$, em comparação com Nelore $(58,69 \%)$, Lorenzoni et al. (1986) atribuíram tal resultado ao fato de que Holandês não é uma raça especializada para corte. Segundo Vaz et al. (2001), que estudaram os fatores que regulam o rendimento de carcaça em animais $\mathrm{HN}$, esta característica está diretamente relacionada com o volume do trato digestório cheio e vazio, sendo que as raças leiteiras apresentaram maior seleção para produção de leite, aumentando diretamente o consumo e, conseqüentemente, o tamanho do trato digestório.

Entre os animais $\mathrm{H}$ e $\mathrm{HN}$, não foi verificada diferença nos rendimentos de carcaça, que foram de 
Tabela 2 - Médias e erro-padrão (EP) para peso de abate, de carcaça, quebra ao resfriamento, rendimento de carcaça e percentagem dos cortes comerciais dos novilhos, de acordo com o grupo genético

Table 2 - Means and standard error (SE) for slaughter weight, carcass weight, chilling loss, dressing percentage and commercial cuts percentages of steers, according to the genetic group

\begin{tabular}{|c|c|c|c|c|c|}
\hline \multirow[t]{2}{*}{$\begin{array}{l}\text { Característica } \\
\text { Characteristic }\end{array}$} & \multicolumn{3}{|c|}{$\begin{array}{l}\text { Grupo genético } \\
\text { Genetic group }\end{array}$} & \multirow[t]{2}{*}{$\begin{array}{l}\mathrm{EP} \\
S E\end{array}$} & \multirow[t]{2}{*}{$\mathrm{P}>\mathrm{F}$} \\
\hline & Hereford $(\mathrm{H})$ & $1 / 2$ Jersey $1 / 2 \mathrm{H}$ & 5/8 H 3/8 Nelore & & \\
\hline $\begin{array}{l}\text { Peso de abate, } \mathrm{kg} \\
\text { Slaughter weight, } \mathrm{kg}\end{array}$ & 379,9 & 346,6 & 371,3 & 10,28 & 0,0823 \\
\hline $\begin{array}{l}\text { Peso de carcaça quente, } \mathrm{kg} \\
\text { Hot carcass weight, } \mathrm{kg}\end{array}$ & $200,6^{\mathrm{a} *}$ & $171,8^{\mathrm{b}}$ & $200,8^{a}$ & 5,93 & 0,0028 \\
\hline $\begin{array}{l}\text { Peso de carcaça fria, } \mathrm{kg} \\
\text { Cold carcass weight, } \mathrm{kg}\end{array}$ & $195,1^{\mathrm{a}}$ & $167,8^{b}$ & $196,2^{\mathrm{a}}$ & 6,14 & 0,0050 \\
\hline $\begin{array}{l}\text { Quebra ao resfriamento, } \% \\
\text { Chilling loss, \% }\end{array}$ & 2,70 & 2,37 & 2,37 & 0,38 & 0,7730 \\
\hline $\begin{array}{l}\text { Rendimento de carcaça quente, } \% \\
\text { Hot dressing percentage, } \%\end{array}$ & $52,79^{\mathrm{a}}$ & $49,56^{\mathrm{b}}$ & $54,08^{\mathrm{a}}$ & 4,66 & 0,0001 \\
\hline $\begin{array}{l}\text { Rendimento de carcaça fria, } \% \\
\text { Cold dressing percentage, } \%\end{array}$ & $51,35^{\mathrm{a}}$ & $48,38^{\mathrm{b}}$ & $52,80^{\mathrm{a}}$ & 4,75 & 0,0001 \\
\hline $\begin{array}{l}\text { Dianteiro, } \% \\
\text { Forequarter, } \%\end{array}$ & 37,38 & 37,40 & 37,38 & 2,72 & 0,9986 \\
\hline $\begin{array}{l}\text { Costilhar, \% } \\
\text { Sidecut, \% }\end{array}$ & 14,15 & 15,04 & 15,05 & 2,05 & 0,1436 \\
\hline $\begin{array}{l}\text { Serrote, } \% \\
\text { Sawcut, } \%\end{array}$ & 48,47 & 47,55 & 47,61 & 9,34 & 0,3602 \\
\hline
\end{tabular}

* a $\mathrm{e}^{\mathrm{b}}$, na linha, são diferentes $(\mathrm{P}<0,05)$ pelo teste Tukey.

${ }^{* a}$ and ${ }^{b}$, within a line, are different $(P<.05)$ by Tukey test.

52,79 e $54,08 \%$, respectivamente. Estudando as características de carcaça de animais $\mathrm{H}$ e $\mathrm{HN}$ terminados em confinamento, Restle et al. (1999c) verificaram maior rendimento de carcaça nos animais mestiços $(53,6 \%)$ em relação aos puros $(49,7 \%)$, sendo que tanto os animais mestiços quanto os puros mostraram valores de rendimento de carcaça inferiores aos verificados no presente trabalho, o que Restle et al. (1999a) atribuem ao fato desses novilhos serem abatidos aos 24 meses de idade.

Ainda na Tabela 2, pode-se verificar que a quebra ao resfriamento foi similar entre os genótipos estudados, assim como as porcentagens dos cortes comerciais da carcaça $(\mathrm{P}>0,05)$. Comparando animais de uma raça de corte e outra leiteira, Jardim et al. (1984) observaram maior porcentagem de serrote em animais Holandês em relação aos Hereford (46,51 contra $45,49 \%$ ), sendo os últimos superiores na porcentagem de costilhar da carcaça $(15,16$ contra 16,33\%). Em machos não-castrados abatidos aos dois anos de idade, Müller \& Chagas (1993) observaram maior porcentagem de costilhar em animais $\mathrm{H}$ em relação aos $5 / 8$ europeu $3 / 8$ zebu.

Moletta \& Restle (1996a) verificaram 16,02 e $14,48 \%$ de costilhar, respectivamente, em novilhos
Aberdeen Angus e Nelore. Flores (1997) obteve a seguinte equação quadrática positiva para a característica porcentagem de costilhar: $\mathrm{Y}=34,9226-$ $0,4743 \mathrm{X}+0,0029 \mathrm{X}^{2}$, em que $\mathrm{X}$ é a porcentagem de $\mathrm{H}$ no cruzamento. A maior porcentagem de costilhar na carcaça está correlacionada ao acúmulo de gordura neste corte, característico dos animais que atingem elevado grau de acabamento em sistemas de produção intensivos (Restle et al., 1999c; Vaz, 1999).

Constam na Tabela 3 os resultados referentes às medidas de desenvolvimento da carcaça, conformação e área de Longissimus dorsi. Observa-se que o comprimento de carcaça e o comprimento de braço foram similares $(\mathrm{P}>0,05)$ entre os genótipos. Já o comprimento de perna foi superior $(\mathrm{P}<0,0408)$ nos novilhos $\mathrm{HN}$ em relação aos $\mathrm{JH}$, sendo que ambos não diferiram dos animais puros.

Müller \& Chagas (1993) observaram menor comprimento de perna em animais Hereford que em 5/8 europeu $3 / 8$ zebu, sendo que o perímetro de braço foi maior nos primeiros. O menor comprimento dos membros em animais europeus em relação aos zebuínos foi relatado nos estudos conduzidos por Perobelli et al. (1995) e Vaz (1999), os quais afirmam que os animais europeus apresentam membros mais curtos, 
porém com maior musculosidade, expressos, principalmente, nas características perímetro de braço, espessura de coxão e conformação. No presente trabalho, observa-se que os animais europeus puros apresentaram maior espessura de coxão que os $\mathrm{HN}$, mas o teste de comparação de médias mostrou que não houve diferença $(\mathrm{P}>0,05)$ entre esses genótipos no perímetro de braço e conformação, sendo que, nestas duas características, os animais $\mathrm{He} \mathrm{HN}$ foram superiores aos JH. A conformação da carcaça foi classificada como "regular mais" para os animais $\mathrm{H}$ (9,88 pontos), "regular menos" nos JH ( 7,75 pontos) e "boa menos" para os HN (10,25 pontos).

Também estudando o cruzamento de bovinos $\mathrm{H}$ com uma raça leiteira (Holandês), Becker (1978) verificaram tendência, embora sem diferença significativa, de os animais $\mathrm{H}$ apresentarem melhor conformação em relação aos 1/2 H 1/2 Holandês. Avaliando animais $\mathrm{H}$ em cruzamento com zebuínos da raça Nelore, Flores (1997) observou conformação classificada como "boa mais" nos $\mathrm{H}$ e 3/4 H 1/4 Nelore e "boa típica" nos 5/8 H 3/8 Nelore.
Também a área de Longissimus dorsi, que é uma medida indicativa da musculosidade da carcaça (Müller, 1987), foi maior nos animais $\mathrm{H}\left(55,46 \mathrm{~cm}^{2}\right) \mathrm{e}$ HN $\left(56,97 \mathrm{~cm}^{2}\right)$ em relação aos JH $\left(46,89 \mathrm{~cm}^{2}\right)$, porém, quando esta característica foi ajustada em relação a $100 \mathrm{~kg}$ de carcaça fria, esta diferença deixou de existir, o que provavelmente foi reflexo do maior peso de carcaça dos dois primeiros. Restle et al. (1999c) também verificaram que a área de músculo Longissimus dorsi, ajustada para $100 \mathrm{~kg}$ de peso de carcaça, não diferiram entre os animais $\mathrm{H}$ puros $\mathrm{e}$ mestiços H x Nelore. Trabalhos como os de Berg \& Butterfield (1976), Crouse et al. (1989) e Sherbeck et al. (1995) também demonstram que esta característica é influenciada por fatores como tamanho do animal e nível alimentar.

$\mathrm{Na}$ Tabela 3, observa-se que a espessura de gordura subcutânea da carcaça foi de 6,25; 4,69; e $6,74 \mathrm{~mm}$, respectivamente, para $\mathrm{H}, \mathrm{JH}$ e $\mathrm{HN}$ $(\mathrm{P}>0,1069)$. Ajustando-se essas médias para o peso de carcaça dos animais, os valores passam a ser 3,23; 2,76; e 3,43 mm, citados na mesma ordem ( $P>0,3906)$.

Tabela 3 - Médias e erro-padrão (EP) para comprimento de carcaça, de perna e de braço, perímetro de braço, espessura de coxão, espessura de gordura, conformação e área de músculo longissimus dorsi (ALD) de novilhos de diferentes grupos genéticos

Table 3 - Means and standard error (SE) for carcass, leg and arm length, arm perimeter, cushion thickeness, fat thickeness, conformation and longissimus dorsi area (LDA) of steers of different genetic groups

\begin{tabular}{|c|c|c|c|c|c|}
\hline \multirow[t]{2}{*}{$\begin{array}{l}\text { Característica } \\
\text { Characteristic }\end{array}$} & \multicolumn{3}{|c|}{$\begin{array}{l}\text { Grupo genético } \\
\text { Genetic group }\end{array}$} & \multirow[t]{2}{*}{$\begin{array}{l}\mathrm{EP} \\
S E\end{array}$} & \multirow[t]{2}{*}{$\mathrm{P}>\mathrm{F}$} \\
\hline & Hereford $(\mathrm{H})$ & $1 / 2$ Jersey $1 / 2 \mathrm{H}$ & 5/8 H 3/8 Nelore & & \\
\hline Comprimento de carcaça, cm & 117,9 & 118,1 & 116,2 & 1,31 & 0,5569 \\
\hline $\begin{array}{l}\text { Carcass length, } \mathrm{cm} \\
\text { Comprimento de perna, } \mathrm{cm} \\
\text { Leg length, } \mathrm{cm}\end{array}$ & $62,2^{\mathrm{ab} *}$ & $61,4^{\mathrm{b}}$ & $63,9^{\mathrm{a}}$ & 0,66 & 0,0408 \\
\hline $\begin{array}{l}\text { Comprimento de braço, } \mathrm{cm} \\
\text { Arm length, } \mathrm{cm}\end{array}$ & 32,9 & 32,5 & 33,7 & 0,48 & 0,1897 \\
\hline $\begin{array}{l}\text { Perímetro de braço, } \mathrm{cm} \\
\text { Arm perimeter, } \mathrm{cm}\end{array}$ & $34,6^{\mathrm{a}}$ & $32,8^{b}$ & $34,0^{\mathrm{a}}$ & 0,44 & 0,0238 \\
\hline $\begin{array}{l}\text { Espessura de coxão, } \mathrm{cm} \\
\text { Cushion thickness, } \mathrm{cm}\end{array}$ & $22,9^{\mathrm{a}}$ & $20,1^{b}$ & $20,4^{b}$ & 0,54 & 0,0037 \\
\hline $\begin{array}{l}\text { Espessura de gordura, mm } \\
\text { Fat thickness, mm }\end{array}$ & 6,25 & 4,69 & 6,74 & 0,68 & 0,1069 \\
\hline $\begin{array}{l}\text { Esp. gord. / } 100 \mathrm{~kg} \text { carcaça, mm } \\
\text { Fat thickness, } \mathrm{mm} / 100 \mathrm{~kg} \text { carcass }\end{array}$ & 3,23 & 2,76 & 3,43 & 0,35 & 0,3906 \\
\hline $\begin{array}{l}\text { Conformação, pontos }{ }^{+} \\
\text {Conformation, points }{ }^{+}\end{array}$ & $9,88^{\mathrm{a}}$ & $7,75^{\mathrm{b}}$ & $10,20^{\mathrm{a}}$ & 0,26 & 0,0001 \\
\hline $\begin{array}{l}\text { ALD }, \mathrm{cm}^{2} \\
L D A, \mathrm{~cm}^{2}\end{array}$ & $55,46^{\mathrm{a}}$ & $46,89^{\mathrm{b}}$ & $56,97^{\mathrm{a}}$ & 2,18 & 0,0077 \\
\hline $\begin{array}{l}\text { ALD }, \mathrm{cm}^{2} / 100 \mathrm{~kg} \text { carcaça, } \mathrm{mm} \\
L D A, \mathrm{~cm}^{2} / 100 \mathrm{~kg} \text { carcass, } \mathrm{mm}\end{array}$ & 28,38 & 28,09 & 29,04 & 0,86 & 0,7310 \\
\hline
\end{tabular}

${ }^{* a} \mathrm{e}^{\mathrm{b}}$, na linha, são diferentes $(\mathrm{P}<0,05)$ pelo teste Tukey.

$+10-12=$ boa, $7-9=$ regular

* $a$ and ${ }^{b}$, within a line, are different $(P<.05)$ by Tukey test.

$+10-12=$ good, $7-9=$ regular .

R. Bras. Zootec., v.31, n.5, p.1973-1982, 2002 
Embora sem diferença estatística, devido ao alto coeficiente de variação da característica $(34,22 \%)$, nota-se tendência de os animais mestiços Jersey apresentarem menor acabamento que os genótipos compostos por raças de corte (H e HN). Becker (1978) observou melhor acabamento em animais H e seus mestiços com raças de corte em relação aos animais $1 / 2 \mathrm{H} 1 / 2$ Holandês.

Comparando novilhos Nelore e Holandês, Lorenzoni et al. (1986) observaram $2 \mathrm{~mm}$ a menos de espessura de gordura nos animais da raça leiteira $(7,8$ contra 5,8 mm), enquanto os mestiços das duas raças, com 50 e 75\% de sangue Holandês, apresentaram 7,0 e $6,2 \mathrm{~mm}$, respectivamente. No cruzamento entre $\mathrm{H}$ e Nelore, Restle et al. (1999c) verificaram 4,33; 5,02; 4,95; e 3,53 mm, respectivamente, para os graus de sangue $100,62,50$ e $25 \%$ de $\mathrm{H}$.

Observando-se a Tabela 4, que mostra os resultados referentes à composição física da carcaça, observa-se que não houve diferença entre os genótipos para as porcentagens de músculo $(\mathrm{P}>0,8922)$, gordura $(\mathrm{P}>0,5656)$ e osso $(\mathrm{P}>0,6661)$, assim como para as relações músculo/osso $(\mathrm{P}>0,9171)$ e músculo + gordura/osso $(\mathrm{P}>0,6305)$.

Ao terminarem, em confinamento, novilhos de raça britânica em cruzamento com Nelore, Flores et al. (1999) não encontraram diferença na percentagem de músculo de animais $\mathrm{H}$ e 3/4 H 1/4 Nelore, sendo de 63,0 e $65,6 \%$, respectivamente. Na comparação entre novilhos $\mathrm{H}$ puros e em cruzamento com diferentes graus de sangue Nelore, abatidos aos 24 meses, Restle et al. (1999c) observaram grande similaridade para a percentagem de músculo, que foi de 62,5 e $63,0 \%$, respectivamente, para $\mathrm{H}$ e $\mathrm{HN}$, assim como para a porcentagem de gordura na carca- ça, que foi de 22,4 e 22,5\%, citados na mesma ordem.

Na Tabela 5, apresentam-se os valores médios referentes à maturidade fisiológica e pH da carcaça, cor, textura e marmoreio da carne. Na avaliação da maturidade fisiológica, observa-se que esta característica se mostrou similar entre os grupos genéticos avaliados ( $\mathrm{P}>0,7666)$, apresentando valores de 13,38 pontos para os animais $\mathrm{H}, 13,63$ pontos para os $\mathrm{JH} \mathrm{e}$ 13,50 pontos para os $\mathrm{HN}$. Em trabalho realizado por Restle et al. (1997), foram verificadas semelhanças entre os valores de maturidade fisiológica de animais de diferentes genótipos $\mathrm{H}$ x Nelore, abatidos com idade jovem.

$\mathrm{O}$ pH da carcaça fria foi bastante similar ( $\mathrm{P}>0,7286)$ entre os genótipos, variando de 5,49 nos HN a 5,51 nos H. Vaz \& Restle (2000) afirmam que animais $\mathrm{H}$ abatidos aos quatorze meses de idade podem apresentar grande variação no $\mathrm{pH}$ da carcaça, alterando significativamente as características organolépticas e sensoriais da carne (Lawrie, 1970; Boggs \& Merkel, 1981; Di Marco, 1994).

Nota-se, na Tabela 5, que a classificação média da coloração ficou entre "vermelha" e "vermelha viva", verificando-se que os animais HN apresentaram coloração muito próxima da ideal "vermelha viva" (4,88 pontos). No estudo realizado por Wheeler et al. (1990), em que utilizaram animais H e uma raça zebuína (Brahman), não foi observada diferença na coloração da carne dos animais. Restle et al. (1997) observaram carne com coloração mais clara em animais HN em relação aos H e 3/4 H 1/4 Nelore. Já Restle et al. (1999c), terminando animais aos 24 meses de idade, observaram valores máximos na pontuação para coloração da carne dos animais $\mathrm{H}$, HN e 3/4 H 1/4 Nelore.

Tabela 4 - Médias e erro-padrão (EP) para composição física da carcaça de novilhos de diferentes grupos genéticos Table 4 - Means and standard error (SE) for carcass physical composition of steers of different genetic groups

\begin{tabular}{|c|c|c|c|c|c|}
\hline \multirow[t]{2}{*}{$\begin{array}{l}\text { Característica } \\
\text { Characteristic }\end{array}$} & \multicolumn{3}{|c|}{$\begin{array}{l}\text { Grupo genético } \\
\text { Genetic group }\end{array}$} & \multirow[t]{2}{*}{$\begin{array}{l}\mathrm{EP} \\
S E\end{array}$} & \multirow[t]{2}{*}{$\mathrm{P}>\mathrm{F}$} \\
\hline & Hereford $(\mathrm{H})$ & 1/2 Jersey $1 / 2 \mathrm{H}$ & 5/8 H 3/8 Nelore & & \\
\hline Músculo, \% & 60,48 & 61,07 & 60,56 & 0,95 & 0,8922 \\
\hline $\begin{array}{l}\text { Muscle, \% } \\
\text { Gordura, \% } \\
\text { Fat, \% }\end{array}$ & 24,90 & 23,65 & 24,83 & 0,92 & 0,5656 \\
\hline $\begin{array}{l}\text { Osso, \% } \\
\text { Bone, \% }\end{array}$ & 14,85 & 15,21 & 14,83 & 0,33 & 0,6661 \\
\hline $\begin{array}{l}\text { Relação músculo/osso } \\
\text { Muscle/bone relation }\end{array}$ & 4,09 & 4,03 & 4,10 & 0,12 & 0,9171 \\
\hline $\begin{array}{l}\text { Relação músculo + gordura/osso } \\
\text { Muscle }+ \text { fat/bone relation }\end{array}$ & 5,77 & 5,59 & 5,79 & 0,16 & 0,6305 \\
\hline
\end{tabular}

R. Bras. Zootec., v.31, n.5, p.1973-1982, 2002 
Tabela 5 - Médias e erro-padrão (EP) para maturidade fisiológica, pH da carcaça, cor, textura e marmoreio da carne dos novilhos, de acordo com o grupo genético

Table 5 - Means and standard error (SE) for physiologic maturity, carcass $\mathrm{pH}$, meat color, texture and marbling of steers, according to the genetic group

\begin{tabular}{|c|c|c|c|c|c|}
\hline \multirow[t]{2}{*}{$\begin{array}{l}\text { Característica } \\
\text { Characteristic }\end{array}$} & \multicolumn{3}{|c|}{$\begin{array}{l}\text { Grupo genético } \\
\text { Genetic group }\end{array}$} & \multirow[t]{2}{*}{$\begin{array}{l}\mathrm{EP} \\
S E\end{array}$} & \multirow[t]{2}{*}{$\mathrm{P}>\mathrm{F}$} \\
\hline & Hereford $(\mathrm{H})$ & 1/2 Jersey $1 / 2 \mathrm{H}$ & 5/8 H 3/8 Nelore & & \\
\hline Maturidade fisiológica, pontos & 13,38 & 13,63 & 13,50 & 0,24 & 0,7666 \\
\hline $\begin{array}{l}\text { Physiologic maturity, points } \\
\mathrm{pH} \text { (após } 24 \text { hs de resfriamento) } \\
\text { pH (after } 24 \text { hs of chilling) }\end{array}$ & 5,51 & 5,50 & 5,49 & 0,02 & 0,7286 \\
\hline $\begin{array}{l}\text { Cor, pontos } * \\
\text { Meat color, points } *\end{array}$ & 4,38 & 4,13 & 4,88 & 0,26 & 0,1465 \\
\hline $\begin{array}{l}\text { Textura, pontos } \\
\text { Texture, points } \\
+\end{array}$ & 4,50 & 4,75 & 4,38 & 0,24 & 0,3306 \\
\hline $\begin{array}{l}\text { Marmoreio, pontos \# } \\
\text { Marbling, points }\end{array}$ & 6,00 & 6,63 & 8,13 & 1,05 & 0,3600 \\
\hline
\end{tabular}

* Variação de 1 a 5 pontos, sendo 1 = escura e 5 = vermelha viva.

+ Variação de 1 a 5 pontos, sendo 1 = muito grosseira e $5=$ muito fina.

\#Variação de 1 a 18 pontos, sendo 1-3 = traços, 16-18 = abundante.

+ Variation from 1 to 5 points, being $1=$ very coarse and $5=$ very fine.

*Variation from 1 to 5 points, being $1=$ dark and $5=$ bright red.

\# Variation from 1 to 18 points, being 1-3 = traces, 16-18 = abundant.

Em relação à textura da carne, observa-se que a média para os três grupos genéticos ficou entre "fina" e "muito fina", sendo que o grupo que mais se aproximou da classificação ideal (muito fina) foi o dos animais JH com 4,75 pontos. Restle et al. (1999c), ao compararem animais He mestiços H x Nelore, e Feijó et al. (1997), utilizando animais Nelore e F1 Simental $\mathrm{x}$ Nelore, não observaram diferença na textura da carne entre os diferentes genótipos. Porém, há trabalhos de pesquisa que indicam que, quando se aumenta o grau de sangue zebuíno no genótipo de uma raça taurina, a textura da carne torna-se mais grosseira (Crouse et al., 1989; Wheeler et al., 1990). Flores (1997) também verificou regressão linear para a textura da carne, que foi mais fina, com o incremento de sangue $\mathrm{H}$ no genótipo dos animais.

Com relação ao marmoreio, os grupos genéticos apresentaram classificação de "leve mais" a "pequena", não apresentando diferença estatística $(\mathrm{P}>0,3600)$. Müller \& Chagas (1993) classificaram como "leve" o marmoreio na carne de machos $\mathrm{H}$, enquanto nos $5 / 8$ Aberdeen Angus 3/8 Nelore essa característica foi classificada como "traços". Moletta \& Restle (1996b) observaram maior marmoreio classificado como "pequeno menos" (7,33 pontos) em animais Aberdeen Angus, enquanto nos Nelore o marmoreio foi "leve mais" ( 6,16 pontos). Já em animais $\mathrm{H}$ e mestiços $\mathrm{H} \mathrm{x}$ Nelore, Restle et al. (1997) e Restle et al. (1999c) não observaram diferença no grau de marmoreio entre os genótipos. Entretanto, trabalhos de pesquisa reportam diferenças na marmorização de animais de raças britânicas, em comparação com suas cruzas com raças zebuínas, como os resultados de Wheeler et al. (1990), que verificaram maior grau de marmoreio para os animais Hereford em comparação aos animais Brahman, e de Huffman et al. (1990), os quais observaram que, à medida que o grau de sangue Brahman aumentou no genótipo, a marmorização da carne diminuiu.

Os valores médios referentes às perdas ao descongelamento e cocção, características sensoriais da carne, força de cisalhamento das fibras musculares e teor de colágeno total no músculo Longissimus dorsi estão apresentados na Tabela 6. Verifica-se que houve diferença $(\mathrm{P}<0,0247)$ na perda ao descongelamento, tendo os animais $\mathrm{HN}$ apresentado maior perda $(9,62 \%)$ em relação aos animais $\mathrm{H}(7,48 \%)$ e $\mathrm{JH}$ $(7,17 \%)$, sendo estes dois últimos similares entre si. Já para perda à cocção, não foi observada diferença ( $\mathrm{P}>0,5026$ ), sendo os valores obtidos de 28,$74 ; 26,98$; e $29,59 \%$, respectivamente, para $\mathrm{H}, \mathrm{JH}$ e $\mathrm{HN}$.

De acordo com Müller \& Robaina (1981), diminuições nas perdas ao descongelamento são verificadas em animais mais jovens ao abate e de melhor grau de acabamento e marmoreio. No presente experimento, embora os animais tenham sido abatidos com idade reduzida, a espessura de gordura 
e o marmoreio não apresentaram variação entre os diferentes genótipos. Moletta \& Restle (1996b) citam $7,51 \%$ de quebra ao descongelamento, em animais zebuínos, enquanto, nos animais de raça britânica, o valor foi de 5,27\%. Os resultados citados por Restle et al. (1999c) mostram maiores perdas ao descongelamento e cocção para animais $\mathrm{H}(8,8$ e $41,1 \%$, respectivamente) abatidos aos 24 meses do que para os animais $\mathrm{H}$ do presente trabalho $(7,48$ e $28,74 \%$, na mesma ordem) abatidos aos 14 meses, o que pode ratificar as afirmações de Müller \& Robaina (1981).

Os valores superiores para perda ao descongelamento dos animais HN haviam sido relatados por Flores (1997), quando verificou que a perda ao descongelamento é maior quando a porcentagem de sangue Nelore é incrementada ao genótipo de animais mestiços $\mathrm{H}$, fazendo com que a suculência da carne diminua, característica que pode estar relacionada com o temperamento dos animais, conforme discutido por Vaz \& Restle (2000). Entretanto, no presente experimento, a diferença entre os grupos genéticos avaliados não foi suficiente para afetar a suculência da carne ( $\mathrm{P}>0,3738)$, que obteve classificação "levemente acima da média". Rocha et al. (1997) reportaram similaridade na suculência da carne dos animais de diferentes genótipos
H x Nelore, abatidos aos 14 meses de idade.

A característica palatabilidade também não se mostrou diferente estatisticamente $(\mathrm{P}>0,6216)$ entre os grupos genéticos avaliados, sendo que, de acordo com a pontuação média obtida, os resultados foram classificados como "levemente acima da média". Ao estudarem diversos genótipos de zebuínos em cruzamento com taurinos, Crouse et al. (1989) verificaram que a palatabilidade foi similar entre os genótipos. Segundo Restle et al. (1996), a palatabilidade da carne está associada com várias características, entre as quais o marmoreio. Nesse trabalho, os pesquisadores verificaram aumento da palatabilidade da carne de animais Charolês, à medida que o grau de marmorização da carne se elevou. No presente experimento, o teor de marmoreio foi similar $(\mathrm{P}>0,3600)$ entre os grupos de novilhos, acompanhando os resultados observados para palatabilidade.

A maciez da carne também apresentou similaridade entre os genótipos ( $\mathrm{P}>0,9031)$. De acordo com a pontuação obtida no experimento, a carne dos novilhos foi classificada como "muito macia". Em animais abatidos com 24 meses de idade, Restle et al. (1999c) verificaram carne "levemente acima da média" para animais H e HN. Segundo Restle et al.

Tabela 6 - Médias e erro-padrão (EP) para perda ao congelamento e à cocção, suculência, palatabilidade, maciez, força de cisalhamento (WBS) e teor de colágeno no músculo Longissimus dorsi dos novilhos de diferentes grupos genéticos

Table 6 - Means and standard error (SE) for thawing loss, cooking loss, juiciness, palatability, tenderness, Shear and total collagen in the Longissimus muscle of steers of different genetic groups

\begin{tabular}{|c|c|c|c|c|c|}
\hline \multirow[t]{2}{*}{$\begin{array}{l}\text { Característica } \\
\text { Characteristic }\end{array}$} & \multicolumn{3}{|c|}{$\begin{array}{l}\text { Grupo genético } \\
\text { Genetic group }\end{array}$} & \multirow[t]{2}{*}{$\begin{array}{l}\mathrm{EP} \\
S E\end{array}$} & \multirow[t]{2}{*}{$\mathrm{P}>\mathrm{F}$} \\
\hline & Hereford $(\mathrm{H})$ & 1/2 Jersey $1 / 2 \mathrm{H}$ & 5/8 H 3/8 Nelore & & \\
\hline $\begin{array}{l}\text { Perda ao descongelamento, } \% \\
\text { Thawing loss, } \%\end{array}$ & $7,48^{\mathrm{b} *}$ & $7,17^{\mathrm{b}}$ & $9,62^{\mathrm{a}}$ & 0,63 & 0,0247 \\
\hline $\begin{array}{l}\text { Perda à cocção, } \% \\
\text { Cooking loss, } \%\end{array}$ & 28,74 & 26,98 & 29,59 & 1,58 & 0,5026 \\
\hline $\begin{array}{l}\text { Suculência, pontos } \\
\text { Juiciness, points }\end{array}$ & 5,45 & 5,08 & 5,96 & 0,43 & 0,3738 \\
\hline $\begin{array}{l}\text { Palatabilidade, } \text { pontos }^{+} \\
\text {Palatabily, points }{ }^{+}\end{array}$ & 5,93 & 5,64 & 6,06 & 0,31 & 0,6216 \\
\hline $\begin{array}{l}\text { Maciez, pontos }{ }^{+} \\
\text {Tenderness, points }\end{array}$ & 7,00 & 7,11 & 7,25 & 0,40 & 0,9031 \\
\hline $\begin{array}{l}\text { WBS, kgf } \\
\text { Shear, kgf }\end{array}$ & 6,12 & 4,98 & 5,54 & 0,41 & 0,1696 \\
\hline $\begin{array}{l}\text { Colágeno, mg / g músculo } \\
\text { Total collagen, } \mathrm{mg} / \mathrm{g} \text { muscle }\end{array}$ & 2,68 & 2,89 & 2,80 & 0,27 & 0,8483 \\
\hline
\end{tabular}

R. Bras. Zootec., v.31, n.5, p.1973-1982, 2002 
(1999b), na produção do superprecoce, o consumidor é beneficiado, devido à melhoria na maciez da carne, pois a redução da idade de abate de dois para um ano de idade pode melhorar a maciez da carne em $30 \%$. Ao medir-se mecanicamente a maciez da carne, pelo aparelho "Warner Bratzler Shear", os genótipos também foram similares $(\mathrm{P}>0,1696)$, obtendo-se valores de 6,$12 ; 4,98$; e 5,54 kgf, respectivamente, para os animais $\mathrm{H}, \mathrm{JH}$ e $\mathrm{HN}$.

O teor de colágeno total no músculo Longissimus dorsi também foi semelhante entre os genótipos (P>0,8483). Segundo autores como Restle et al. (1997) e Vaz \& Restle (2000), que trabalharam com animais $\mathrm{H}$ e seus mestiços com Nelore, a maciez da carne não-maturada está correlacionada, também, com o conteúdo de colágeno. Em alguns trabalhos de pesquisa, constatou-se maior maciez da carne em animais europeus em relação a animais zebuínos (Perobelli et al., 1994; Restle et al., 1999a). Vaz (1999) verificou que, mesmo em cruzamento, os animais com maior porcentagem de sangue zebuíno apresentaram carne de menor maciez que animais com maior grau de sangue europeu. Entretanto, no presente experimento, esta diferença não foi observada entre os animais Hereford e 5/8 Hereford 3/8 Nelore.

\section{Conclusões}

Novilhos Hereford e 5/8 Hereford 3/8 Nelore apresentaram maior rendimento e peso de carcaça, melhor conformação e maior área de Longissimus dorsi que os $1 / 2$ Jersey $1 / 2$ Hereford.

O teor de gordura na carcaça, as características organolépticas e a maciez da carne não foram afetados pela participação de sangue Jersey ou Nelore ao genótipo Hereford.

A carne de animais 5/8 Hereford 3/8 Nelore apresentou maior perda ao descongelamento que a carne de animais Hereford e 1/2 Jersey 1/2 Hereford.

Bezerros filhos de touros Jersey apresentaram carne de qualidade semelhante à dos Hereford e 5/8 Hereford 3/8 Nelore.

\section{Literatura Citada}

ADAMS, A.Jr. Croosbreeding beef. Gainesville: University of Florida Press, 1973. 519p.

BECKER, A.S. Produtividade da raça Hereford e em cruzamentos com Charolês, Holandês e Santa Gertrudis. Santa Maria: Universidade Federal de Santa Maria, 1978, 125p. Dissertação (Mestrado em Zootecnia) - Universidade Federal de Santa Maria, 1978.

R. Bras. Zootec., v.31, n.5, p.1973-1982, 2002
BERG, R.T.; BUTTERFIELD, R.M. New concepts of cattle growth. Sydney: Sydney University Press, 1976. 240p.

BOGGS, D.L.; MERKEL, R.A. Live animal: carcass evaluation and selection manual. Iowa: Michigan State University, 1981. 199p.

CROUSE, J.D.; CUNDIFF, L.V.; KOCH, R.M. et al. Comparisons of Bos indicus and Bos taurus inheritance for carcass beef characteristics and meat palatability. Journal of Animal Science, v.67, n.9, p.2661-2668, 1989.

DI MARCO, O.N. Crecimiento y respuesta animal. Balcarce: Associación Argentina de Producción Animal, 1994. 129p.

FEIJÓ, G.L.D.; EUCLIDES FILHO, K.; FIGUEIREDO, G.R. et al. Avaliação de carcaças de Nelore e F1's europeu-Nelore a um grau de acabamento constante. In: REUNIÃO ANUAL DA SOCIEDADE BRASILEIRA DE ZOOTECNIA, 34. 1997, Juiz de Fora. Anais... Juiz de Fora: Sociedade Brasileira de Zootecnia, 1997. p.133-135.

FLORES, J.L.C. Desempenho em confinamento e características de carcaça e da carne de bovinos de diferentes grupos genéticos abatidos aos quatorze meses. Santa Maria: Universidade Federal de Santa Maria, 1997, 109p. Dissertação (Mestrado em Zootecnia) - Universidade Federal de Santa Maria, 1997.

FLORES, J.L.C.; RESTLE, J.; ALVES FILHO, D.C. et al. Características quantitativas da carcaça de bovinos de diferentes grupos genéticos abatidos aos quatorze meses. In: REUNIÃO ANUAL DA SOCIEDADE BRASILEIRA DE ZOOTECNIA, 36., 1999, Porto Alegre. Anais... Porto Alegre: Sociedade Brasileira de Zootecnia, 1999. p.148.

HANKINS, O.G.; HOWE, P.E. Estimation of the composition of beef carcass and cuts. Whashington, D.C.: United States Departament of Agriculture, 1946. 20p. (Technical Bulletin, 926)

HUFFMAN, R.D.; WILLIAMS, S.E.; HARGROVE, D.D. et al. Effects of percentage Brahman and Angus breeding, age season of feeding and slaughter point on feedlot performance and carcass characteristics. Journal of Animal Science, v.68, n.8, p.2243-2252, 1990.

JARDIM, P.O.C.; OSÓRIO, J.C.S.; GUERREIRO, J.V.S.F. et al. Efeito da raça sobre o peso e percentagem dos cortes da carcaça de novilhos. In: REUNIÃO ANUAL DA SOCIEDADE BRASILEIRA DE ZOOTECNIA, 21., 1984, Belo Horizonte. Anais... Belo Horizonte: Sociedade Brasileira de Zootecnia, 1984. p.122.

LAWRIE, R.A. Ciência de la carne. Zaragoza: Acribia, 1970. $342 p$.

LORENZONI, W.R.; CAMPOS, J.; GARCIA, J.A. et al. Ganho de peso, eficiência alimentar e qualidade da carcaça de novilhos búfalos, Nelores, Holandeses e mestiços HolandêsZebu. Revista da Sociedade Brasileira de Zootecnia, v.15, n.6, p.486-497, 1986.

MOLETTA, J.L.; RESTLE, J. Características de carcaça de novilhos de diferentes grupos genéticos terminados em confinamento. Revista da Sociedade Brasileira de Zootecnia, v.26, n.5, p.876-888, 1996a.

MOLETTA, J.L.; RESTLE, J. Influência do grupo genético sobre características qualitativas da carne de novilhos. Revista da Sociedade Brasileira de Zootecnia, v.26, n.5, p.866-875, 1996b.

MÜLLER, L.; CHAGAS, E.C. Estudo de carcaça de touros jovens. In: REUNIÃO ANUAL DA SOCIEDADE BRASILEIRA DE ZOOTECNIA, 30., 1993. Rio de Janeiro. Anais... Rio de Janeiro: Sociedade Brasileira de Zootecnia, 1993. p.190.

MÜLLER, L., ROBAINA, G.P. Qualidade da carne de novilhos de raças britânicas de idade cronológica diferentes. 
In: REUNIÃO ANUAL SOCIEDADE BRASILEIRA DE ZOOTECNIA, 18., 1981, Goiânia. Anais... Goiânia: Sociedade Brasileira de Zootecnia, 1981. p.391.

MÜLLER, L. Normas para avaliação de carcaças e concurso de carcaças de novilhos. 2.ed. Santa Maria: Universidade Federal de Santa Maria, 1987. 31p.

PASCOAL, L.L.; VAZ, R.Z.; ROSO, C. Confinamento versus pastagem na terminação de bovinos. In: RESTLE, J. (Ed.) Confinamento, pastagens e suplementação para produção de bovinos de corte. Santa Maria: Universidade Federal de Santa Maria, 1999. p.178-190.

PEROBELLI, Z.V.; RESTLE, J.; MÜLLER, L. Estudo das carcaças de vacas de descarte das raças Charolês e Nelore. Pesquisa Agropecuária Brasileira, v.30, n.3, p.409-412, 1995.

PEROBELli, Z.V.; MÜLLER, L.; RESTLE, J. Estudo da qualidade das carcaças e da carne de vacas de descarte de dois grupos genéticos. Ciência Rural, v.24, n.3, p.613-616, 1994.

RESTLE, J.; KEPLIN, L.A.S.; VAZ, F.N. et al. Qualidade da carne de novilhos Charolês confinados e abatidos com diferentes pesos. Ciência Rural, v.32, n.8, p.463-466, 1996.

RESTLE, J.; ROCHA, J.B.T.; FLORES, J.L.C. et al. Qualidade da carne de animais Hereford e suas cruzas com Nelore, abatidos aos quatorze meses. In: REUNIÃO ANUAL DA SOCIEDADE BRASILEIRA DE ZOOTECNIA, 34., 1997, Juiz de Fora. Anais... Juiz de Fora: Sociedade Brasileira de Zootecnia, 1997. p.196-198.

RESTLE, J.; BRONDANI, I.L.; BERNARDES, R.A.C. O novilho superprecoce. In: RESTLE, J. (Ed) Confinamento, pastagens e suplementação para produção de bovinos de corte. Santa Maria: Universidade Federal de Santa Maria, 1999a. p.191-214.

RESTLE, J.; BRONDANI, I.L.; FLORES, J.L.C. et al. Desempenho de genótipos de novilhos para abate aos quatorze meses, gerados por fêmeas de dois anos. Pesquisa Agropecuária Brasileira, v.34, n.11, p.2123-2128, 1999 b.

RESTLE, J.; VAZ, F.N.; QUADROS, A.R.B. Características de carcaça e da carne de novilhos de diferentes genótipos de Hereford x Nelore. Revista Brasileira de Zootecnia, v.28, n.6, p.1245-1251, 1999c.
ROCHA, J.B.T.; PEROTTONI, J.; RESTLE, J. et al. Qualidade da carne de animais inteiros de dois grupos genéticos, abatidos aos quatorze meses de idade. In: REUNIÃO ANUAL DA SOCIEDADE BRASILEIRA DE ZOOTECNIA, 34., 1997, Juiz de Fora. Anais... Juiz de Fora: Sociedade Brasileira de Zootecnia, 1997. p.199-201.

SANTIAGO, A.A. Cruzamentos na pecuária bovina. Campinas: Instituto Campineiro de Ensino Agrícola, 1984. 413p.

SAS INSTITUTE. Language reference. Version 6, Cary: 1990. $1042 p$.

SHERBECK, J.A.; TATUM, T.G.; FIELD, J.B. et al. Feedlot performance, carcass traits, and palatability traits of Hereford and Hereford x Brahman steers. Journal of Animal Science, v.73, n.12, p.3613-3620, 1995.

VAZ, F.N. Cruzamento alternado das raças Charolês e Nelore: características de carcaça e da carne de novilhos abatidos aos dois anos. Santa Maria: Universidade Federal de Santa Maria, 1999. 58p. Dissertação (Mestrado em Zootecnia) - Universidade Federal de Santa Maria, 1999.

VAZ, F.N.; RESTLE, J. Aspectos qualitativos da carcaça e da carne de machos Hereford, inteiros ou castrados, abatidos aos quatorze meses. Revista Brasileira de Zootecnia, v.29, n.6, p.1894-1901, 2000.

VAZ, F.N.; RESTLE, J.; ALVES FILHO, D.C. et al. Peso das vísceras e rendimento de carcaças de novilhos ou novilhas Braford superprecoces, terminados com suplementação em pastagem cultivada sob pastejo controlado. In: REUNIÃO ANUAL DA SOCIEDADE BRASILEIRA DE ZOOTECNIA, 38., 2001, Piracicaba. Anais... Viçosa, MG: Sociedade Brasileira de Zootecnia, 2001. p.1531-1532.

WHEELER, T.L.; SAVELL, J.W.; CROSS, H.R. et al. Mechanisms associated with the variation in tenderness of meat from Brahman and Hereford cattle. Journal of Animal Science, v.68, n.9, p.4206-4220, 1990. 